\title{
Use of the Glasgow-Blatchford score during the COVID-19 pandemic needs more rigorous research
}

A very important paper by Young-II Kim et al. [1] was published recently in Endoscopy. The authors found that the Glasgow-Blatchford score (GBS) was inferior to the Rockall score in predicting the need for urgent hemostatic intervention for tumor-associated upper gastrointestinal bleeding (UGIB), leading to poor performance (area under the receiver operating characteristic curve [AUROC] 0.56). This study is crucial for patient risk stratification for UGIB during the COVID-19 pandemic, and we would like to draw your attention toward it.

The COVID-19 pandemic has severely affected the practice of gastrointestinal (GI) endoscopy worldwide because upper $\mathrm{Gl}$ endoscopy has been recognized as an aerosol-generating procedure that increases the risk of COVID-19 infection [2]. Thus, the endoscopic management of patients with UGIB now presents a dilemma. The pre-endoscopy risk scores, such as GBS, are based on pre-pandemic research and have not been validated by large-scale studies during the COVID-19 pandemic. A recent case series [3] has shown that six UGIB patients with COVID and GBS $>7$ did not require endoscopy and were conservatively managed, which did not accord with the relevant European Society for Gastrointestinal Endoscopy (ESGE) guideline [4]. The latter recommends only that patients with a GBS score of $0-1$ do not require endoscopy. Thus, the performance of the GBS has seemed to be especially limited during the COVID-19 pandemic [3]. According to Laursen et al. [5], the low-risk threshold for defining UGIB patients who do not require inpatient endoscopy and hospitalization could be increased to $G B S<3$.
In conclusion, the COVID-19 pandemic remains a worldwide challenge, and its impact on GI endoscopy and UGIB detection could be increasingly significant. Raising the GBS threshold or developing a new and accurate risk score before endoscopy in UGIB patients will be critical in the prevention of a UGIB healthcare crisis. We hope a more rigorous study will be conducted in the near future.

\section{Competing interests}

The authors declare no conflicts of interest.

The authors

Zhihui Duan, Shengyun Zhou, Zongxian Niu Department of Endoscopy, Xingtai People's Hospital, Xingtai 054000, Hebei Province, China

\section{Corresponding author}

\section{Zhihui Duan, MM}

Department of Endoscopy, Xingtai People's Hospital, No.16 Hongxing Street, Xingtai 054000, Hebei Province, China

15131988129@163.com

\section{References}

[1] Kim YI, Choi IJ, Lee JY et al. Comparison of the performance of risk scoring systems for tumor bleeding in patients with inoperable gastric cancer. Endoscopy 2020; 52: 359367

[2] Gralnek IM, Hassan C, Beilenhoff U et al. ESGE and ESGENA Position Statement on gastrointestinal endoscopy and the COVID19 pandemic. Endoscopy 2020; 52: 483490
[3] Cavaliere K, Levine C, Wander P et al. Management of upper $\mathrm{Gl}$ bleeding in patients with COVID-19 pneumonia. Gastrointest Endosc 2020; 92: 454-455

[4] Gralnek IM, Dumonceau JM, Kuipers EJ et al. Diagnosis and management of nonvariceal upper gastrointestinal hemorrhage: European Society of Gastrointestinal Endoscopy (ESGE) Guideline. Endoscopy 2015; 47: a1a 46

[5] Laursen SB, Gralnek IM, Stanley AJ. Raising the threshold for hospital admission and endoscopy in upper gastrointestinal bleeding during the COVID-19 pandemic. Endoscopy 2020; 52: 930-931

\section{Bibliography}

Endoscopy 2021; 53: 209

DOI 10.1055/a-1300-2132

ISSN 0013-726X

published online 19.11.2020

(c) 2020. Thieme. All rights reserved. Georg Thieme Verlag KG Rüdigerstraße 14, 70469 Stuttgart, Germany 